\title{
Procurement Method Selection for Building Maintenance Projects: The Case of Malaysian Public Universities
}

\author{
Shirley Jin Lin Chua, Azlan Shah Ali, Anuar Alias \\ Faculty of Built Environment, University of Malaya, Kuala Lumpur, Malaysia \\ Email: shirleychua88@um.edu.my, asafab@um.edu.my, anuar a@um.edu.my
}

Received May 2014

\begin{abstract}
The purpose of this paper is to implement and validate a decision making framework for building maintenance projects. The growing importance of maintenance sector not only in Malaysia but also increasingly globalized, the difficulty in selecting an appropriate procurement method and lack of research in this area provide an impetus for this research. There were 19 procurement selection criteria identified. In addition, there were 4 types of procurements methods which include outsourcing by specialist term contract, outsourcing by tendered schedule term contract, outsourcing by repair and maintenance contract and outsourcing by measured term contract identified to be the most popular procurement methods adapted by public universities currently and at the same time were considered most important. The decision making framework was developed based on AHP technique and principles. Expert Choice Software was employed as development tool where the criteria and alternatives were integrated into the framework. Finally, structured interview was conducted to validate the framework developed. The validation process was carried out through structured interview with selected public university.
\end{abstract}

\section{Keywords}

Analytic Hierarchy Process, Expert Choice Software, Procurement Method, Building Maintenance Management, Public Universities

\section{Introduction}

Procurement system of a project is a key factor which contributes to the overall client satisfaction and project success. Ng et al. [1] agreed that project success is depends on the selection and use of a suitable procurement strategy. This is supported by Hui and Tsang [2] which claimed that the two main success factors in building maintenance management are selecting the most appropriate procurement strategy and implement it in a proper way. Improving the universities' building maintenance management systems by selecting the most appropriate procurement method is significant if universities wish to provide conducive learning environment and research centre for university organization, students, faculty members, parents and other users. Hashim et al. [3] claimed 
that it is a complex and intimidate task for the client and the client's advisers to select the most appropriate procurement method due to the amplification of demand on quality services for building or space, changes in business environment and the ever evolving market trend resulting in emergence of various procurement strategy. Thus, the tasks of decision makers to select the most appropriate procurement method becoming more challenging.

Alhazmi and McCaffer [4] mentioned that the nature in selecting procurement method requires a suitable decision-making technique to evaluate the procurement methods against certain criteria systematically. This paper presents a study of the selection of procurement method for building maintenance management through the use of Multiple criteria decision making (MCDM) particularly Analytic Hierarchy Process (AHP). The finding of this study will act as a tool to guide the decision maker to select the most suitable and appropriate procurement method that will improve the maintenance management in Malaysia.

\section{Building Maintenance Procurement Strategy}

Masterman [5] explained that project procurement act as the organizational structure where a group of people are brought together and organized systematically in term of their responsibilities, duties, roles and interrelationship between them. Ibbs and Chih [6] mentioned that the use of a suitable procurement method can affect project efficiency and success. This statement is true for local, regional or global project in scope.

Different procurement method will have different effect on the time, quality and cost of the project therefore it is very crucial to consider all factors in the selection of the most appropriate procurement strategy. This is because each type of procurement system has its own feature and peculiarity that will have effect on the quality, cost and time of the project which is more likely to be known as project performance. Thus, selecting an appropriate procurement method is very essential to obtain optimum project performance.

There were 4 types of procurement methods identified to be the most popular procurement methods adapted by public universities currently which include:

1) Outsourcing by Measured Term Contract (MTC);

2) Outsourcing by Specialist Term Contract (STC);

3) Outsourcing by Tendered Schedule Term contract;

4) Outsourcing by Repair and Maintenance Contract (RMC).

\subsection{Possible Assessment Procurement Selection Criteria}

Love et al. (1998) highlighted that owners that have similar nature do not certainly have similar needs. In fact, the needs rely on many factors and are usually specific to the particular project. It is essential to establish a list of procurement selection criteria before various procurement methods were evaluated. The procurement selection criteria should reflect the requirements and characteristics of the client, project and external environment (Luu et al., 2003a; Kumaraswamy and Dissanayak, 2001 and Ambrose and Tucker, 1999). A list of criteria for procurement methods selection in building maintenance project was established. There were 19 criteria which were categorized in three main categories that were clients' requirement, project characteristic and external environment or factor shown in Table 1.

\subsection{Decision Making Framework}

Ratnasabapathy and Rameezdeen [7] highlighted that it is strategically essential to make sure the selection of procurement method is done systematically and in a closely controlled manner. Masterman [8] claimed that the practice of procurement selection available is rather unstructured and unplanned. Many clients select procurement methods in a cursory way simply based upon biased conservative decisions and past experience. In fact, some clients even employ certain procurement method by default without making a deliberated choice. Thus, Cheung et al. [9] suggested that the use of the AHP technique in decision making process enables the decision maker to structure a complex problem in the form of a simple hierarchy and to evaluate a large number of qualitative and quantitative factors in a systematic manner under multiple criteria. It is a logical way for people to make decisions.

Multiple Criteria Decision Making (MCDM) particularly the Analytic Hierarchy Process (AHP) was employed in this study. Decision is made based on multiple criteria that enables the decision maker to derive his 
Table 1. List of final procurement selection criteria.

\begin{tabular}{cc}
\hline C1 & Criteria \\
\hline C1.1 & Clients' Requirements \\
C1.2 & Experience contractor availability \\
C1.3 & Quality level \\
C1.4 & Knowledge of the strategy \\
C1.5 & Degree of responsibility \\
C1.6 & Client's financial capability \\
C1.7 & Price competition \\
C1.8 & Time Certainty \\
C1.9 & Speed \\
C1.10 & Public accountability \\
C1.11 & Clarity of scope \\
C1.12 & Involvement of owner in the project \\
C1.13 & Working relationship \\
C1.14 & Intuition and pass experience \\
C1.15 & Client in house technical capability \\
C2 & Price or cost certainty \\
C2.1 & Project Characteristic \\
C2.2 & Existing building condition \\
C3 & Project size \\
C3.1 & External Environment/Factor \\
& Government policy \\
\hline &
\end{tabular}

own set of importance weightings for the selection criteria according to the building or project characteristics. The application of AHP and Expert choice which able to calculate the judgment consistency assure that the decision maker judgments are consistent and the final decision is made well. The decision makers are able to reexamine and revise the judgments for all level of the hierarchy and it shows where the inconsistency exists and how to minimize it in order to improve the decision.

\section{Research Design}

The implementation and validation process was carried out through structured interview with a selected public university. Structure interview is chosen so that the researcher can explain the framework in detail to the respondents, clarify any doubts arises by the interviewees and at the same time the researcher able to examine the level of understanding of the respondents towards the topic and the framework. The two main purposes of this structured interview are:-

1) The interviewees are requested to do a pair-wise comparison with the assessment criteria and procurement option which has been developed in the Expert Choice software

2) The interviewees also requested to evaluate the proposed decision making framework in term of its capability, applicability and validity.

During the interview, the framework was demonstrated to the interviewee. Then, the interviewees were asked to run the framework and were asked to evaluate the framework in term of capability, applicability and validity.

\section{Results and Discussion}

The validation process was carried out through structured interviews with the maintenance personnel that involve in the decision making process in selecting procurement method for building maintenance work. The in- 
terviewee is selected from the maintenance and facilities' maintenance management department of one of the public university in Malaysia.

The building maintenance department in the university named as Department of Development and Maintenance. The university was established on 18th of May 1970. The structured interview was conducted on 25th of April 2013 with an assistant head of quantity surveying department. Quantity surveying department deals matters relating to contracts, thus the interviewee who had 17 years of experience were appropriate to be interviewed because she involved in the decision making process in selecting the most appropriate procurement strategy. The interview session was held in a meeting room and the all the pairwise comparison judgments was done and evaluation process was made after discussion.

All the pairwise comparison judgments made in Expert Choice software were synthesis to obtain vector of priorities. All the vector of priority for main criteria, sub criteria and alternatives were tabulated in Table 2. Based on the result obtained, the interviewee priority main factor in selecting the most appropriate procurement method for maintenance of air-conditioning services are project characteristics (0.540), external environment or factors (0.297) and clients' requirements (0.163). The abbreviation used for sub criteria can be referred to Table 3. All main criteria judgments consistency ratio (CR) were 0.01 that were less than $0.10(<0.10)$ which represent good consistency.

The result of priority obtained for pairwise comparison among sub criteria under clients' requirements in selecting the most appropriate procurement method for maintenance of air-conditioning services and ranking can be referred to Table 3. The consistency ratio value is 0.09 which was lesser than $0.10(<0.10)$, therefore the judgments consistency is acceptable. The two sub criteria under project characteristics (C2) which were existing building condition (C2.1) and project size (C2.2) obtained equally 0.500 priority vector. This result revealed that existing building condition and project size were equally important when selecting the most appropriate procurement method for maintenance of air-conditioning services. While for objective or policy of organization (C3.1) and government policy (C3.2) which is under external environment or factors (C3), the interviewees feel that policy of organization government policy (0.750) are more important compared to objective or policy of organization (0.250). Both judgments for sub criteria under C2 and C3 obtained $0.00(<0.10)$ consistency ratio, thus the consistency ratio was accepted.

From Table 2, the result indicated that for sub criteria under clients' requirements (C1) that were C1.6, C1.13, $\mathrm{C} 1.14$ and $\mathrm{C} 1.15$ has more strength when performing outsourcing by repair and maintenance contract. Sub criteria C1.4, C1.5, C1.7, C1.8, C1.9, C1.10, C1.11, C1.12 and C1.14 perform better under outsourcing by specialist term contract while none perform better under outsourcing by tendered schedule term contract. There are 3 sub criteria have more strength under outsourcing by measured term contract which were C1.1, C1.2 and C1.3. While for sub criteria under project characteristic (C2) and external environment or factor (C3), C2.1, C2.2, C3.1 and C3.2 perform better under outsourcing by specialist term contract although C3.1 and 3.2 has equally performance for outsourcing by specialist term contract and outsourcing by repair and maintenance Contract. All the judgments made obtained value of CR less that $0.10(<0.10)$ that was acceptable.

Table 4 revealed vectors of priorities for the alternatives with respect to the main factor and alternatives' vector of overall priorities. The results indicated that outsourcing by specialist term contract $(0.402)$ was more preferable among the four alternatives for clients' requirements. As the value of consistency is $0.09<0.10$, the consistency judgment was acceptable. While for project characteristics (C2), outsourcing by specialist term contract (0.487) was also more preferable. On the other hand, external environment or factors (C3) obtained 0.368 priority vector for both outsourcing by specialist term contract and outsourcing by repair and maintenance contract. The consistency ratio for both project characteristics (C2) and external environment or factors (C3) obtained $0.06(<0.10)$ consistency ratio that was acceptable.

The vector of overall priorities for the four alternatives as shown in Table 4 indicated that outsourcing by specialist term contract (0.432) which obtained the highest of vector of overall priorities is the best procurement method maintenance for air-conditioning services in that particular university. This is followed by outsourcing by repair and maintenance contract $(0.300)$, outsourcing by Measured Term Contract $(0.160)$ and outsourcing by tendered schedule term contract $(0.108)$.

\section{Conclusion}

The proposed framework was well received by the interviewee and the interviewee admitted that the selection of the procurement process proposed was decided on a judgmental basis which was not simply based upon pre- 


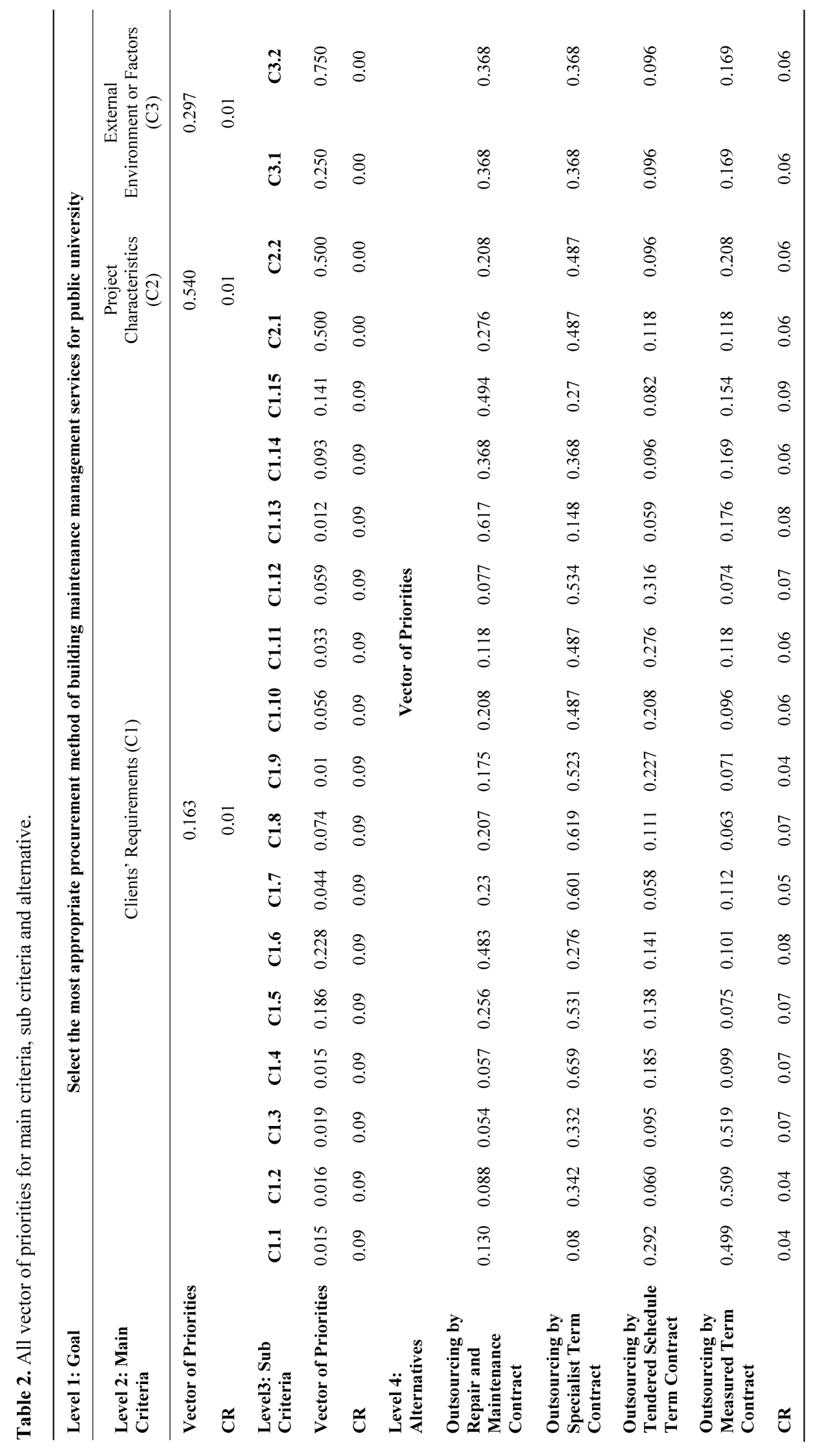


Table 3. All vector of priorities for main criteria, sub criteria and alternative.

\begin{tabular}{cccc}
\hline Abbreviation Used & Description & Vector of Priorities & Ranking \\
\hline C1.1 & Experienced contractor availability & 0.015 & 12 \\
C1.2 & Quality level & 0.016 & 11 \\
C1.3 & Knowledge of the strategy & 0.019 & 10 \\
C1.4 & Degree of responsibility & 0.015 & 12 \\
C1.5 & Client's financial capability & 0.186 & 2 \\
C1.6 & Price competition & 0.228 & 1 \\
C1.7 & Time Certainty & 0.044 & 8 \\
C1.8 & Speed & 0.074 & 5 \\
C1.9 & Public accountability & 0.01 & 14 \\
C1.10 & Clarity of scope & 0.056 & 7 \\
C1.11 & Involvement of owner in the project & 0.033 & 9 \\
C1.12 & Working relationship & 0.059 & 6 \\
C1.13 & Intuition and pass experience & 0.012 & 13 \\
C1.14 & Client in house technical capability & 0.093 & 4 \\
C1.15 & Price or cost certainty & 0.141 & 3 \\
\hline
\end{tabular}

Table 4. Vector of overall priorities with respect to main criteria.

\begin{tabular}{|c|c|c|c|c|}
\hline Main Criteria & $\begin{array}{c}\text { Clients' } \\
\text { Requirements } \\
\text { (C1) }\end{array}$ & $\begin{array}{c}\text { Project } \\
\text { Characteristics } \\
\text { (C2) }\end{array}$ & $\begin{array}{c}\text { External } \\
\text { Environment/Factors } \\
\text { (C3) }\end{array}$ & \multirow{3}{*}{$\begin{array}{r}\text { Vector o } \\
\text { Overall } \\
\text { Prioritie }\end{array}$} \\
\hline Vector of Priorities & 0.163 & 0.540 & 0.297 & \\
\hline CR & 0.01 & 0.01 & 0.01 & \\
\hline Alternatives & \multicolumn{4}{|c|}{ Vector of Priorities } \\
\hline Outsourcing by Repair and Maintenance Contract & 0.328 & 0.242 & 0.368 & 0.300 \\
\hline Outsourcing by Specialist Term Contract & 0.402 & 0.487 & 0.368 & 0.432 \\
\hline Outsourcing by Tendered Schedule Term Contract & 0.14 & 0.107 & 0.096 & 0.108 \\
\hline Outsourcing by Measured Term Contract & 0.13 & 0.163 & 0.169 & 0.160 \\
\hline CR & 0.09 & 0.06 & 0.06 & 0.05 \\
\hline${ }^{*} \mathrm{CR}=$ Consistency Ratio & & & & \\
\hline
\end{tabular}

vious experience and perception. The evaluations done by interviewee regarding the proposed decision making framework revealed the Decision Making Framework for Procurement Method Selection of Building Maintenance Management for Public Universities developed was good in terms of capability, applicability and validity in assisting the decision-makers to select the most appropriate procurement method in building maintenance work. Thus, the proposed decision making framework will be capable to assist the decision-makers to select the most appropriate procurement method.

\section{Acknowledgements}

The authors gratefully acknowledge the financial support of the University of Malaya Research Grant (UMRG), grant no RG183/12SUS established at the University of Malaya, Sustainability Science Research Cluster.

\section{References}

[1] Ng, S.T., Luu, D.T. and Chen, S.E. (2002) Decision Criteria and Their Subjectivity in Construction Procurement Selection. The Australian Journal of Construction Economics and Building, 2, 70-80.

[2] Hui, E.Y.Y. and Tsang, A.H.C. (2004) Sourcing Strategies of Facilities Management. Journal of Quality in Mainten- 
ance Engineering, 10, 85-92. http://dx.doi.org/10.1108/13552510410539169

[3] Hashim, M., Li, M.C.Y., Yin, N.C., et al. (2006) Factors Influencing the Selection of Procurement Systems by Clients. International Conference on Construction Industry, 2006, Padang, 1-10.

[4] Alhazmi, T. and McCaffer, R. (2000) Project Procurement System Selection Model. Journal of Construction Engineering and Management, 126, 176-184. http://dx.doi.org/10.1061/(ASCE)0733-9364(2000)126:3(176)

[5] Masterman, J.W.E. (1996) Building Procurement Systems: An Introduction. Spon Press, London.

[6] Ibbs, W. and Chih, Y.-Y. (2011) Alternative Methods for Choosing an Appropriate Project Delivery System (PDS). Facilities, 29, 527-541. http://dx.doi.org/10.1108/02632771111178418

[7] Ratnasabapathy, S. and Rameezdeen, R. (2007) A Decision Support System for the Selection of Best Procurement System in Construction. Built-Environment Sri Lanka, 7, 53-43.

[8] Masterman, J.W.E. (1992) An Introduction to Building Procurement Systems. Spon Press, London.

[9] Cheung, S.O., Lam, T.I., Leung, M.Y., et al. (2001) An Analytical Hierarchy Process Based Procurement Selection Method. Construction Management and Economics, 19, 427-437. http://dx.doi.org/10.1080/014461901300132401 